\title{
O princípio da demanda efetiva de keynes como contra- ataque definitivo à lei de say dos economistas (neo)clássicos
}

\author{
André Cutrim Carvalho \\ David Ferreira Carvalho²
}

\begin{abstract}
Resumo:
Na Teoria Geral, Keynes apresentou o seu entendimento sobre o Princípio da Demanda Efetiva. Para isso, ele desenvolveu uma nova taxonomia conceitual, o que trouxe dificuldades para a compreensão da nova mensagem contida na sua obra, sobretudo para aqueles economistas formados na tradição da ortodoxia (neo)clássica. Portanto, o objetivo fundamental do presente artigo é apresentar o Princípio da Demanda Efetiva de Keynes como contra-ataque definitivo à Lei de Say dos economistas (neo)clássicos. A verdadeira prova da validade da Teoria Geral não é a lógica nem os fatos, mas sim a utilidade da sua aplicação no mundo real em que vivemos.

Palavras-chave: Teoria Geral; Keynes; Princípio da Demanda Efetiva.
\end{abstract}

Keynes' principle of effective demand as a definitive counter-attack against say's law upheld by the (neo) classical economists

\begin{abstract}
Abastract:
In General Theory, Keynes presented his understanding of the Principle of Effective Demand. For this, he developed a new conceptual taxonomy, which brought difficulties to the understanding of the new message contained in his Work, especially for those economists trained in the tradition of (neo) classical orthodoxy. Therefore, the fundamental objective of this paper is to present Keynes's Principle of Effective Demand as a definitive counterattack to Say's (neo) classical economists. The true proof of the validity of the General Theory is not logic, not facts, but the usefulness of its application in the real world in which we live.
\end{abstract}

Keywords: General Theory; Keynes; Principle of Effective Demand.

Classificação JEL: E00; E10; E12.

1 Doutor em Desenvolvimento Econômico e pós-doutor em Economia pelo Instituto de Economia (IE) da Universidade Estadual de Campinas (Unicamp). Docente da Faculdade de Ciências Econômicas (FACECON) e do Programa de Pós-Graduação em Gestão de Recursos Naturais e Desenvolvimento Local na Amazônia (PPGEDAM), da Universidade Federal do Pará (UFPA); e também professor visitante do IE/UNICAMP. E-mail: andrecc83@gmail.com

2 Doutor e pós-doutor em Economia pelo Instituto de Economia (IE) da Universidade Estadual de Campinas (UNICAMP). Docente da Faculdade de Ciências Econômicas (FACECON), vinculada ao Instituto de Ciências Sociais Aplicadas (ICSA) da Universidade Federal do Pará (UFPA). E-mail: david.fcarvalho@yahoo.com.br 


\title{
1. Introdução
}

A questão da demanda efetiva está circunscrita, ainda que de forma inadequada, em dois planos: o histórico e o teórico. No plano histórico, a questão da demanda efetiva aparece associada às recorrentes crises da economia capitalista, a exemplo da grande depressão dos anos 30 , no bojo da qual recebeu o mais importante tratamento teórico de Keynes e Kalecki.

No plano teórico, a questão da demanda efetiva aparece vinculada ao problema da demanda efetiva - na literatura keynesiana - ou ao problema de realização na tradição marxista. Pode-se dizer que a questão da demanda efetiva nas duas acepções é colocada, inicialmente, como sendo um problema econômico: o problema da insuficiência da demanda efetiva, permanente ou temporária, como discutido em Possas e Baltar (1981) e Possas (1987).

Marx (1980), ao discutir sua teoria do dinheiro, já tinha identificado a possibilidade de uma crise por insuficiência da demanda efetiva, pois tinha ciência de que o vendedor conduz o comprador ao mercado, mas o ato de gastar, para adquirir a mercadoria oferecida pelo vendedor, é uma decisão autônoma do possuidor do dinheiro - o comprador.

Marx (1980) afirmara que ninguém pode vender sem que alguém compre. Assim sendo, quando o comprador em geral deixa de adquirir mercadorias do vendedor, então o dinheiro (poder de compra) retido pelo comprador cria um blecaute no circuito M-D-M que pode originar uma crise por insuficiência de demanda. Esse fato é revelado por Marx (1980, p. 126-127) nos seguintes termos:

\begin{abstract}
Ninguém pode vender, sem que alguém compre. Mas ninguém é obrigado a comprar imediatamente, apenas por ter vendido. A circulação rompe com as limitações de tempo, de lugar e individuais, impostas pela troca de produtos, ao dissociar a identidade imediata que, nesta última, une a alienação do produto próprio e a aquisição do alheio, gerando a antítese entre venda e compra. Dizer que esses atos são independentes entre si, que possuem uma unidade interior, equivale a dizer que essa unidade interior transparece através de antíteses externas. Se essa independência exterior dos dois atos, - interiormente dependentes por serem complementares, - prossegue se afirmando, além de certo ponto, contra ela prevalece, brutalmente, a unidade, por meio de uma crise.
\end{abstract}

De fato, em uma economia mercantil-monetária simples, as formas de realização das trocas dinheiro-mercadoria implicam a possibilidade, mas apenas a possibilidade, de crises. "Para a conversão dessa possibilidade em realidade é mister todo um conjunto de condições, que ainda não existem numa circulação simples de mercadorias", lembra Marx (1980, p. 127). Essas condições, entretanto, estão presentes em uma economia monetária da produção, isto é, em uma economia especificamente capitalista.

O presente artigo foi organizado em cinco seções, além desta seção introdu- 
tória, a saber: na segunda seção, discute-se o princípio da demanda efetiva - também chamado de PDE, formulado pelo Prof. Mário Luiz Possas, com o propósito de confrontá-lo com o princípio dos mercados de Say (Lei de Say); na terceira, é apresentado o princípio da demanda efetiva nos termos originais de Keynes; na quarta, discute-se o princípio da demanda efetiva como o contra-ataque definitivo à Lei de Say dos economistas (neo)clássicos, além da relação entre demanda efetiva, propensão a consumir e multiplicador da renda; e, por fim, são apresentadas as considerações finais na última seção.

\section{A formulação geral do princípio da demanda efetiva}

Para resgatar o sentido da insuficiência de demanda efetiva, Possas (1987) propõe não só como uma questão teórica própria da dinâmica econômica, mas também como um princípio da demanda efetiva em sua forma simples e geral. A teoria da demanda efetiva tem duas dimensões no campo da investigação: uma dimensão histórica e outra teórica. Entretanto, qualquer que seja a formulação, ela requer a inserção de certas hipóteses, e mesmo da história, como é o caso da teoria da demanda efetiva usada pelo Keynes para explicar a causa do desemprego numa economia monetária da produção.

Não obstante, para compreender o significado do princípio da demanda efetiva, o que interessa mais é o uso da lógica para o estabelecimento das condições de sua vigência. Possas (1987, p. 50) procurou demonstrar que "o princípio da demanda efetiva é um princípio (ou axioma) que, por ser verdadeiro em si mesmo, prescinde de hipóteses adicionais".

Em linhas gerais, o princípio da demanda efetiva nada mais é do que um axioma. A diferença entre um axioma e um teorema está na necessidade da demonstração formal de que o último é verdadeiro, como foi o caso do teorema de Pitágoras na geometria. Na economia, o fato de que toda compra corresponde a uma venda é tão verdadeiro em si mesmo que não precisa de demonstração.

Contudo, ainda assim é necessário provar sua veracidade por lógica. No caso do princípio da demanda efetiva, e sua antítese à Lei de Say, não há contradição do fato observado de que toda compra corresponde a uma venda, ou de que não há compra sem venda, mas quando a Lei de Say afirma que a "oferta cria a sua própria demanda” está em jogo não o fato de que toda a venda corresponde a uma compra, mas o sentido da causalidade da determinação do ato mercantil: é a compra que determina a venda ou é a venda que determina a compra? Não se trata da história de quem veio primeiro, o ovo ou a galinha.

A expressão mercantil significa troca. Pode-se ter uma economia mercantil mediada ou não mediada pelo dinheiro. No primeiro caso, tem-se uma economia de trocas diretas, a exemplo da economia de escambo, em que se troca diretamente produto por produto. Em uma economia de escambo não é possível identificar 
quem é o comprador, ou quem é o vendedor, porque simplesmente essas categorias (comprador e vendedor) ainda não existem. As categorias de comprador e vendedor só existem em uma economia mercantil que troca mercadorias (vendedores) por dinheiro (compradores), cujo local de encontro para que o ato mercantil se realize é chamado de mercado.

Em uma economia de escambo têm-se apenas trocadores de produtos, pois não há mercadorias produzidas em grande escala ou escala suficiente, como observa Marx (1980), para serem destinadas ao mercado onde podem ser vendidas pelo seu possuidor em troca do dinheiro (moeda) possuído pelo comprador. O sentido da causalidade do ato mercantil somente pode ser observado numa economia mercantil-monetária, pois nesta é possível identificar tanto o comprador (possuidor do dinheiro) quanto o vendedor (possuidor da mercadoria).

Há dois modelos de economia mercantil-monetária: a economia mercantil simples (M-D-M) e a economia capitalista (D-M-D'). A opção da formulação geral e simples do princípio da demanda efetiva em um contexto de uma economia mercantil-monetária simples justifica-se porque se quer destacar apenas a característica mais geral, isto é, a relação mercantil-monetária.

Cabe destacar, porém, que Keynes tinha clareza de que se tratava, também, de uma economia cindida em classes. Keynes (CW, XXIX, p. 63-64 apud Garlipp, 2008, p. 05) afirma:

Concebemos a organização econômica da sociedade consistindo, de um lado, em um número de firmas ou empreendedores que possuem equipamento de capital e comando sobre os recursos sob a forma de dinheiro, e de outro, em um número de trabalhadores buscando ser empregado.

É claro que uma "economia mercantil simples" é mera abstração destinada a reter as propriedades especificamente mercantis da economia capitalista, e que, por não ter nem existência real nem interesse teórico independente, não pode existir a não ser na forma capitalista. De qualquer maneira, o importante a registrar é que a produção e venda de mercadorias em troca de dinheiro, em suas funções sociais, é suficiente para circunscrever a formulação do princípio da demanda efetiva.

Para a definição do princípio da demanda efetiva não é necessário que o dinheiro (moeda) potencialmente assuma a forma de capital-dinheiro, ou que se realize a transição do modelo de uma economia mercantil simples, M-D-M, para o de uma economia capitalista, D-M-D`. Garlipp (2008, p. 05), entretanto, estabelece uma importante - e necessária - contribuição:

Em uma economia monetária e empresarial, o valor dos bens é realizado pela troca por um equivalente geral da riqueza: o dinheiro. Aumentar o poder de comando sobre a riqueza social é o que suporta a produção dessa economia; é, simultaneamente, motivo e objetivo esperado das operações empresariais. 
E vai além ao resgatar o próprio Keynes (CW, XXIX, p. 81 apud Garlipp, 2008, p. 05) para isso:

\begin{abstract}
Em uma rara referência a Marx, mas não secundária, Keynes aceita a sua "arguta observação" de que "a natureza da produção no mundo atual não é M-D-M, isto é, uma troca de uma mercadoria (ou esforço) por dinheiro com o fito de obter outra mercadoria (ou esforço). Este pode ser o ponto de vista do consumidor privado. Mas não é a atitude do empreendedor, um caso de D-M-D', isto é, começa-se com dinheiro, troca-se por mercadoria (ou esforço) com o objetivo de obter mais dinheiro".
\end{abstract}

Ou seja, conforme Keynes (CW, XXI, p. 89 apud Garlipp, 2008, p. 05), “(...) a firma lida todo o tempo com somas de dinheiro. Ela não tem qualquer objetivo no mundo exceto terminar com mais dinheiro do que começou. Essa é a característica essencial de uma economia empresarial": "uma economia em que "o objetivo geral da acumulação de riqueza é o de provocar resultados”, conclui Keynes (CW XIV, p. 113 apud Garlipp, 2008, p. 05).

Para tanto, basta apenas a presença do dinheiro (moeda) com suas funções sociais - unidade de conta, meio de troca, meio de pagamento e reserva de valor - para que o princípio da demanda efetiva seja aceito como válido e o princípio da oferta de Say seja refutado. Apesar disso, é evidente que somente na vigência de uma economia especificamente capitalista, ou seja, numa economia monetária da produção, a demanda efetiva adquire os supostos necessários para uma atuação relevante quanto aos seus efeitos na dinâmica capitalista.

O contexto histórico-institucional da validade do princípio da demanda efetiva é tipicamente o de uma economia monetária da produção, ou seja, de uma economia mercantil-monetária cuja melhor representação é a economia especificamente capitalista. Uma economia mercantil-monetária, em termos simples e gerais, pode ser caracterizada pelos seguintes elementos:

i) a produção é realizada por produtores (firmas ou indivíduos) privados independentes e é destinada ao intercâmbio no mercado;

ii) não há mecanismos de regulação consciente da produção, sendo o próprio mercado a instância responsável pela distribuição do produto social;

iii) o produto social de uma nação é sua riqueza social expressa no valor de uma coleção de mercadorias;

iv) o dinheiro é o equivalente geral que serve de referência para que o valor social de cada mercadoria possa ter expressão relativa, aceita por todos, nos preços; 
v) o dinheiro, como equivalente geral, assume as funções sociais de unidade de conta dos valores monetários, meio de troca, meio de pagamento e reserva de valor ${ }^{3}$.

Numa economia monetária da produção, marcada pela produção e circulação de mercadorias e do dinheiro, o sentido da determinação da causalidade foi formulado por Possas (1987, p. 51) nos seguintes termos: "Em qualquer ato de compra e venda tomado isoladamente, produz-se um fluxo monetário - pagamento de um lado, recebimento de outro - decorrente de uma única decisão autônoma: a de efetuar determinado dispêndio."

Essa formulação do princípio da demanda efetiva tem a vantagem lógica de ser simples e ao mesmo tempo geral. Ademais, o princípio da demanda efetiva opõe-se ao princípio dos mercados de Say como uma espécie de antilei da Lei de Say. Contudo, apesar do sugestivo enunciado de Possas, Keynes (1978, p. 80-81), em uma formulação original, já tinha explicitada a essência do princípio da demanda efetiva nos seguintes termos:
À proposição de que a oferta cria sua própria demanda, devo substituir pela proposição de que o gasto cria o seu próprio rendimento, isto é, um rendimento suficiente apenas para atender o gasto. Isso, veremos, é uma proposição mais geral do que a precedente. Esta formulação deve ser considerada no sentido de que uma variação no custo produção agre- gado será compensado por igual variação no gasto agregado, a última é consistente com a desigualdade entre variações no custo de produção e variações no gasto.

Pelo princípio da demanda efetiva, todo ato de compra e venda decorre de uma única decisão autônoma na qual o ato de gastar do comprador determina a renda obtida do vendedor. De fato, isso acontece porque qualquer ato mercantil envolve dois agentes: o vendedor, que é identificado por vender a mercadoria; e o comprador, que é identificado por comprar a mercadoria com dinheiro (moeda). O vendedor é assim chamado por se apresentar como o possuidor da mercadoria, enquanto o comprador é tratado dessa maneira por se apresentar como o detentor do dinheiro - objeto de desejo de todos os agentes por ter aceitação social e ser a forma por excelência do poder de compra em geral.

Embora o vendedor se esforce, com todos os meios (propaganda, descontos e outros mais) que possui para convencer o comprador a adquirir sua mercadoria específica, ele não pode decidir vendê-la se o comprador não quiser. Todavia, quando o ato mercantil (compra e venda) ocorre, produz-se um fluxo monetário - pagamento em moeda de um lado (comprador) e recebimento de moeda do outro

3 A função de meio de pagamento da moeda surge com a concessão do crédito à produção e o comércio de bens. Essa caracterização retém os elementos mínimos de uma economia mercantil-monetária. Ver Marx (1980). 
(vendedor) - e um fluxo real - recebimento da mercadoria específica de um lado (comprador) e entrega da mercadoria específica (vendedor). $\mathrm{O}$ ato mercantil, consequentemente, depende da decisão única e autônoma do comprador (possuidor do dinheiro), e não do vendedor (possuidor da mercadoria) de efetuar determinado gasto que gerará a renda.

Além disso, o ato mercantil-monetário, como um momento instantâneo do ato de compra e venda, dispensa alguma referência teórica ao tempo econômico, simplesmente porque é desnecessário para fins da demonstração lógica do princípio da demanda efetiva. O sentido da determinação da renda pelo gasto é definido no "ato" que, por ser instantâneo, pode prescindir do tempo econômico.

Em uma economia mercantil-monetária, portanto, o fluxo monetário das receitas (vendedores), idêntico ao das despesas (comprador) correspondentes, é determinado pelas decisões individuais dos gastos dos agentes econômicos na aquisição de mercadorias e ativos ${ }^{4}$. O princípio da demanda efetiva pode ser, também, formulado em termos de renda, ou valor adicionado, tal como desenvolvido por Keynes em A Teoria Geral do Emprego, do Juro e da Moeda; ou, simplesmente, Teoria Geral (TG).

Nesse particular, cabe observar, entretanto, que as rendas em geral (salários, aluguéis, juros e lucros) são remunerações monetárias pagas aos proprietários fatores de produção (famílias) pelas firmas pelos serviços prestados, e, como tal, são fluxos monetários que se esgotam tão logo ocorra o ato mercantil-monetário: pagamento de um lado e recebimento de outro. No final, isto é, depois que as famílias recebem seus fluxos de renda, principalmente os trabalhadores (salários), o que elas (proprietárias dos fatores de produção) retêm é poder de compra, ou seja, um estoque de riqueza líquida na forma de dinheiro.

A rigor, um indivíduo não utiliza toda a sua renda recebida previamente na compra de bens e serviços. Na prática, o que realmente um indivíduo possui - logo depois que recebe sua renda corrente - é poder de compra na forma de dinheiro decorrente da renda monetária recebida previamente. Assim, o problema do comprador, quando decide gastar parte da sua renda corrente comprando mercadorias, não é quanto da renda monetária recebida deverá gastar comprando bens e serviços, mas quanto de poder de compra (dinheiro) deverá ele dispor para tomar a decisão autônoma de comprar mercadorias e, desse modo, efetivar o ato mercantil-monetário. Na concepção de Possas (1987, p. 55-56):

4 Não há intenção de tratar aqui das implicações teóricas decorrentes do princípio da demanda efetiva, sobretudo para o confronto com certas formulações habituais - equilíbrio aquém do pleno emprego, da oposição entre lucros e salários, das inflexibilidades de preços, salários e taxas de juros, do equilíbrio entre poupança e investimento - mesmo porque a análise de tais implicações já foi realizada por Possas (1987, p. 59-72). 
Não deve ser esquecido que, numa economia monetária da produção, os gastos dos agentes podem ser financiados não só pela renda monetária corrente, uma das fontes básicas do poder de compra, mas também no mercado monetário (mercado de crédito) no mercado financeiro (mercado de capitais) e pela conversão do patrimônio líquido em liquidez (moeda).

\section{O princípio da demanda efetiva de John Maynard Keynes}

No livro 1, capítulo 3 da Teoria Geral (TG), Keynes apresenta o seu entendimento sobre o Princípio da Demanda Efetiva (PDE). Para isso, o referido autor desenvolve uma nova taxonomia conceitual, o que trouxe dificuldades para a compreensão da nova mensagem contida na TG, sobretudo para aqueles economistas formados na tradição da ortodoxa economia clássica.

De acordo com o PDE, os agentes econômicos determinam o nível do produto e, assim, do emprego quando tomam a decisão de produzir ou de investir. Para Chick (1993, p. 69): “como a decisão de cada agente é tomada no âmbito microeconômico, o Princípio da Demanda Efetiva é formulado tendo em vista o modelo de comportamento da empresa".

Para criticar a Lei de Say e, por conseguinte, os fundamentos da economia clássica, Keynes criou uma nova taxonomia que confere a economia política uma estrutura conceitual diferente. Harrod (1958) havia observado que os críticos mais profundos erraram por supor que Keynes tenha simplesmente substituído um sistema conceitual por outro. É verdade que o plano da principal obra de Keynes consiste, em essência, em uma série de novas definições e em uma reclassificação, mas, em certo sentido, não se pode afirmar dogmaticamente que uma taxonomia é correta e outra não.

A menos que exista uma falha lógica em uma das taxonomias, os fatos podem se acomodar a qualquer das duas. Cada taxonomia deve ser julgada não só pela sua estrutura lógica, mas também pelo uso e aplicação em relação aos problemas e situações reais. O verdadeiro defeito do sistema clássico era que desviava a atenção do que mais necessitava.

Foi a poderosa intuição de Keynes que, realmente, o levou a perceber que a velha taxonomia dos clássicos era inadequada. A elevada capacidade lógica de Keynes permitiu que ele construísse uma nova taxonomia. Para Harrod (1958, p. 534): "a verdadeira prova da validade da Teoria Geral, ainda que isso possa parecer estranho aos olhos dos estudiosos de outros ramos da ciência, não é a lógica, nem os fatos, mas sim a utilidade da sua aplicação no mundo real em que vivemos”.

\subsection{A dimensão microeconômica do Princípio da Demanda Efetiva}

É da natureza das firmas que a decisão de produção de mercadorias para venda futura deva ser feita com base em estimativas de custos e em uma previsão de 
demanda efetiva futura. Como o processo de produção toma tempo, o empresário não tem outra opção a não ser avaliar a demanda efetiva futura para a venda dos seus produtos sem confiar em seus cálculos probabilísticos e em suas conjecturas sobre os acontecimentos econômicos futuros num ambiente econômico marcado por incerteza.

Tanto o custo quanto a demanda se elevam com o aumento do produto, mas, por certo tempo, também os lucros são elevados. É suposto que uma vez que as empresas escolham produzir qualquer volume de produto que considerem que maximizará seus lucros esperados, dadas as estimativas de custo de produção e suas previsões de demanda, então elas contratarão exatamente a quantidade de mão de obra que lhes permitirá produzir tal montante de produto.

O PDE é a generalização dessa proposição microeconômica de determinação do produto da economia como um todo. Nesse contexto, e sob a hipótese de um determinado padrão tecnológico de recursos disponíveis e de custos, o emprego efetivo de certo volume de mão de obra proporcionado por uma firma impõe ao empresário - o agente responsável pela decisão de empregar - duas espécies de gastos:

$1^{\circ}$ ) gastos com os fatores de produção: são os montantes pagos pelo empresário aos fatores de produção por seus serviços habituais. Nesses gastos não entram o que ele paga a outros empresários, sendo que esse tipo de gasto é denominado de custo de fatores do emprego em questão;

$2^{\circ}$ ) gastos com outros empresários: são os montantes pagos pelo empresário a outros empresários pelo que compram, juntamente pelo sacrifício que fazem utilizando o seu equipamento em vez de deixá-lo ocioso. Esse segundo tipo de gasto é denominado de custo de uso do emprego em questão.

A diferença entre o valor da produção resultante da venda de produtos e soma dos custos de fatores e do custo de uso é o lucro ou, como dito por Keynes, a renda do empresário (1). A renda do empresário (lucro), assim definida, é o valor monetário que a firma procura maximizar quando o empresário está decidindo qual o volume de emprego deverá oferecer.

Já o custo de fatores vem a ser a renda dos fatores - salários(w), juros(j) e aluguéis $(\mathrm{g})$ - isto é, a renda que deverá ser recebida pelos proprietários dos fatores de produção do ponto de vista do empresário. $\mathrm{O}$ custo dos fatores mais a renda do empresário (lucro) formam a renda total (y) resultante do emprego que deverá ser oferecido pelo empresário.

É preciso observar, porém, que essa renda total se situa a nível microeconômico e compreende: $y=w+j+g+1$. Nessa condição, entretanto, é possível agora somar as rendas totais de cada empresa para obter a renda agregada da economia como um todo. $\mathrm{Na}$ ótica do empresário, por vezes, é conveniente chamar a renda agregada - custo de fatores mais lucro - resultante de certo volume de emprego de produto desse nível de emprego.

Por outro lado, o preço da oferta agregada da produção, resultante de determinado volume de emprego, nada mais é do que o produto esperado, que é exata- 
mente suficiente para que os empresários considerem vantajoso oferecer o emprego em questão. É bom observar que o preço de oferta agregada ex ante não deve ser confundido com o preço de oferta ex post no sentido comum do termo empregado pela microeconomia convencional.

De fato, o preço de oferta da produção, por ser um conceito ex ante, refere-se ao valor da produção esperado que proporcione o lucro normal da concorrência perfeita, o que significa que o preço de oferta ex ante é igual ao custo primário marginal do emprego pretendido quando o empresário - no plano microeconômico - toma a decisão de produzir bens e serviços para atender uma suposta demanda esperada no futuro.

Não obstante, para obter essa igualdade, Keynes elimina o custo de uso tanto do valor bruto da produção (receita bruta esperada) quanto do preço de oferta agregada (custo total esperado) de determinado volume de produção, de tal modo que ambos os termos possam ser interpretados em termos de valores monetários líquidos em relação ao custo de uso da firma.

Enquanto isso, as somas totais pagas pelo empresário aos fatores de produção (F) e a outros empresários (U) para o emprego em questão são, naturalmente, os valores brutos em relação ao custo de uso. Tomando-se o preço de oferta ex ante que torne vantajoso o empresário decidir empregar um dado volume de emprego, tem-se:

$\mathrm{R}_{\mathrm{t}}^{\mathrm{e}}=\mathrm{C}_{\mathrm{t}}^{\mathrm{e}}$ (condição para a obtenção do lucro normal)

Subtraindo o custo de uso ex ante (U) de ambos os membros de (1), fica:

$\mathrm{R}_{\mathrm{t}}^{\mathrm{e}}-\mathrm{U}=\mathrm{C}_{\mathrm{t}}^{\mathrm{e}}-\mathrm{U}$

Fazendo: $\mathrm{R}_{1}^{\mathrm{e}}=\mathrm{R}_{\mathrm{t}}^{\mathrm{e}}-\mathrm{U} ; \mathrm{C}_{1}^{\mathrm{e}}=\mathrm{C}_{\mathrm{t}}^{\mathrm{e}}-\mathrm{U}$, tem-se:

$\mathrm{R}_{1}^{\mathrm{e}}=\mathrm{C}_{1}^{\mathrm{e}}$

Em termos ex ante, para uma unidade de produção, tem-se:

$\mathrm{R}_{\mathrm{t}}^{\mathrm{e}}=$ valor bruto da produção = receita total bruta;

$\mathrm{C}_{\mathrm{t}}^{\mathrm{e}}=$ preço de oferta da produção = custo total da produção;

$\mathrm{R}_{1}^{\mathrm{e}}=$ valor líquido da produção $=$ receita total líquida

$\mathrm{C}_{1}^{\mathrm{e}}=$ preço de oferta líquido da produção = custo total líquido.

Pode-se, também, apresentar o preço de oferta agregado ex ante em termos de receita e custo marginais. Nesse caso, derivando a receita total e o custo total, obtém-se a receita marginal $\left(R_{m g}^{e}\right)$ e o custo marginal $\left(\mathrm{C}_{\mathrm{mg}}^{\mathrm{e}}\right)$ :

$$
\begin{aligned}
& \mathrm{d}\left(\frac{\mathrm{R}_{\mathrm{t}}^{\mathrm{e}}}{\mathrm{q}}\right)=\mathrm{R}_{\mathrm{mg}}^{\mathrm{e}} ; \\
& \mathrm{d}\left(\frac{\mathrm{C}_{\mathrm{t}}^{\mathrm{e}}}{\mathrm{q}}\right)=\mathrm{C}_{\mathrm{mg}}^{\mathrm{e}} \\
& \text { Igualando (3) a (4), temos: } \\
& \mathrm{R}_{\mathrm{mg}}^{\mathrm{e}}=\mathrm{C}_{\mathrm{mg}}^{\mathrm{e}}
\end{aligned}
$$


Subtraindo o custo de uso (U) de ambos os membros de (5), resulta:

$\mathrm{R}_{\mathrm{t}}^{\mathrm{e}}-\mathrm{U}=\mathrm{C}_{\mathrm{t}}^{\mathrm{e}}-\mathrm{U}$

Fazendo: $\mathrm{R}_{\mathrm{mgl}}^{\mathrm{e}}=\mathrm{R}_{\mathrm{mg}}^{\mathrm{e}}-\mathrm{U} ; \mathrm{C}_{\mathrm{mgl}}^{\mathrm{e}}=\mathrm{C}_{\mathrm{mg}}^{\mathrm{e}}-\mathrm{U}$, então:

$\mathrm{R}_{\mathrm{mgl}}^{\mathrm{e}}=\mathrm{C}_{\mathrm{mgl}}^{\mathrm{e}}$ (condição para obtenção do lucro normal)

Em que:

$\mathrm{R}_{\mathrm{mgl}}^{\mathrm{e}}=$ receita marginal líquida do custo de uso;

$\mathrm{C}_{\mathrm{mgl}}^{\mathrm{e}}=$ custo marginal líquido do custo de uso.

O essencial desses conceitos é que as receitas agregadas e o preço de oferta agregada, ambos líquidos do custo de uso, são definidos de maneira exclusiva e sem ambiguidades por Keynes. Com isso, torna-se possível superar os problemas de agregação dos valores microeconômicos para os valores macroeconômicos. Neste particular, Keynes (1982, p. 60) afirma:

Visto que, evidentemente, o custo de uso depende do grau de integração da indústria e da importância das compras que os empresários realizam entre si, não pode haver definição das somas agregadas pagas pelos empresários, incluindo o custo de uso, que seja independente desses fatores. Há uma dificuldade semelhante na definição de preço de oferta, no sentido comum da expressão, para um produtor individual; e, no caso do preço da oferta agregada da produção em conjunto, corre-se o risco de sérias dificuldades de duplicação que nem sempre foram levadas em conta.

Keynes (1982), todavia, temia que se o preço de oferta agregada da produção, em termos macroeconômicos, fosse interpretado incluindo o custo de uso, os inconvenientes só poderiam ser superados à custa de hipóteses especiais relativas ao grau de integração do grupo de empresas - conforme a sua produção fosse de bens de consumo ou de bens de investimento - hipóteses essas que, em princípio, seriam obscuras, complexas e não corresponderiam aos fatos.

"Se, pelo contrário, o preço de oferta agregada se define como antes, isto é, líquido relativamente ao custo de uso, essas dificuldades desapareceriam”, pondera Keynes (1982, p. 60). Por tudo isso, o Princípio da Demanda Efetiva sob a ótica macroeconômica pode ser visto como uma extensão da determinação do produto e do emprego pela demanda efetiva em uma dimensão microeconômica.

\subsection{A dimensão macroeconômica do Princípio da Demanda Efetiva}

É conveniente para os macroeconomistas, quando analisam a economia como um todo do ponto de vista dos empresários, referirem-se à receita agregada líquida do custo de uso resultante das vendas de bens finais, como o produto (valor adicionado) monetário resultante da quantidade do emprego oferecido. A renda agregada (custo de fatores mais lucro) da economia como um todo deverá ser diferente da totalidade dos gastos monetários realizada num intervalo de tempo, exatamente 
pelo valor monetário do custo de uso.

Apesar do nível de emprego e do produto das firmas individuais dependerem das expectativas das receitas brutas das vendas esperadas, o nível de emprego e do produto da economia como um todo é dependente do produto agregado esperado. Disso deduz-se que, tendo em conta certas condições da técnica, de recursos e de custos dos fatores por unidade de emprego oferecido - para a firma individual, para a indústria em particular, e para a indústria em geral (economia como um todo) -, o volume de emprego da economia como um todo dependerá do nível da receita que os empresários esperam receber (ex ante) da correspondente produção.

É evidente que o volume de emprego efetivo associado à produção de bens e serviços é também expectacional porque depende das decisões do conjunto dos empresários que estão sob condições de incerteza quanto aos resultados esperados no futuro desconhecido. De acordo com Keynes (1982, p. 60):

Um empresário que tenha que tomar uma decisão prática a respeito da sua escala de produção não terá, naturalmente, uma única expectativa, inconteste, sobre qual será a receita esperada da venda dos seus produtos no mercado, mas sim várias expectativas hipotéticas, formuladas com graus variáveis de probabilidade de acerto, das quais uma é escolhida, num ambiente de incerteza, com base no estado de confiança.

Cabe antecipar que Keynes (1982, p. 60) define expectativa da receita esperada do empresário das vendas futuras do seguinte modo:

Por sua expectativa de receita quero dizer, portanto, aquela que, se formulada em condições de certeza, o levaria à mesma conduta que o conjunto das possibilidades mais diversas e vagas que compõem o seu estado de expectativa no instante de tomar sua decisão.

Por conta disso, os empresários, no momento da decisão, empenham-se em estabelecer o volume do emprego no nível em que esperam maximizar a diferença entre a receita esperada e o custo primário de produção que irão desembolsar no pagamento dos fatores para obterem o lucro máximo.

Nota-se que o principal objetivo da TG é propor uma teoria do emprego efetivo cuja quantidade é determinada ex ante, isto é, no momento da tomada de decisão de produzir. Nesse contexto, quando uma decisão de investimento é tomada, dado o estoque de capital fixo, a determinação do emprego efetivo implica também a determinação do produto esperado. É preciso enfatizar que o ponto de partida da teoria da determinação do volume do emprego efetivo é o princípio da demanda efetiva, o qual repousa sobre o modelo de comportamento das empresas, assim no plano microeconômico, mas que pode ser generalizado para o plano macroeconômico, tal como produzido por Keynes (1982).

Para explicar o Princípio da Demanda Efetiva como uma generalização ma- 
croeconômica, Keynes (1982) afirma que o volume de produção e o nível geral do emprego da economia, como um todo, são determinados pela interseção de duas funções do nível de emprego, $\mathrm{N}$, da oferta agregada, $\mathrm{Z}(\mathrm{N})$, e as estimativas da demanda agregada das empresas, $D^{e}(N)$.

O ponto de interseção é chamado de ponto da demanda efetiva. As duas funções são definidas em termos líquidos do custo de uso, pois sua inclusão traria problemas de agregação. A função da oferta agregada incorpora as estimativas dos custos de mão de obra relacionados a cada nível de emprego que daria às empresas o incentivo necessário para levar o nível de emprego até aquele nível planejado. A renda estimada associada a cada nível de emprego é representada pela função da demanda agregada, como mostra a Figura 1.

Figura 1 - Ponto de determinação da Demanda Efetiva

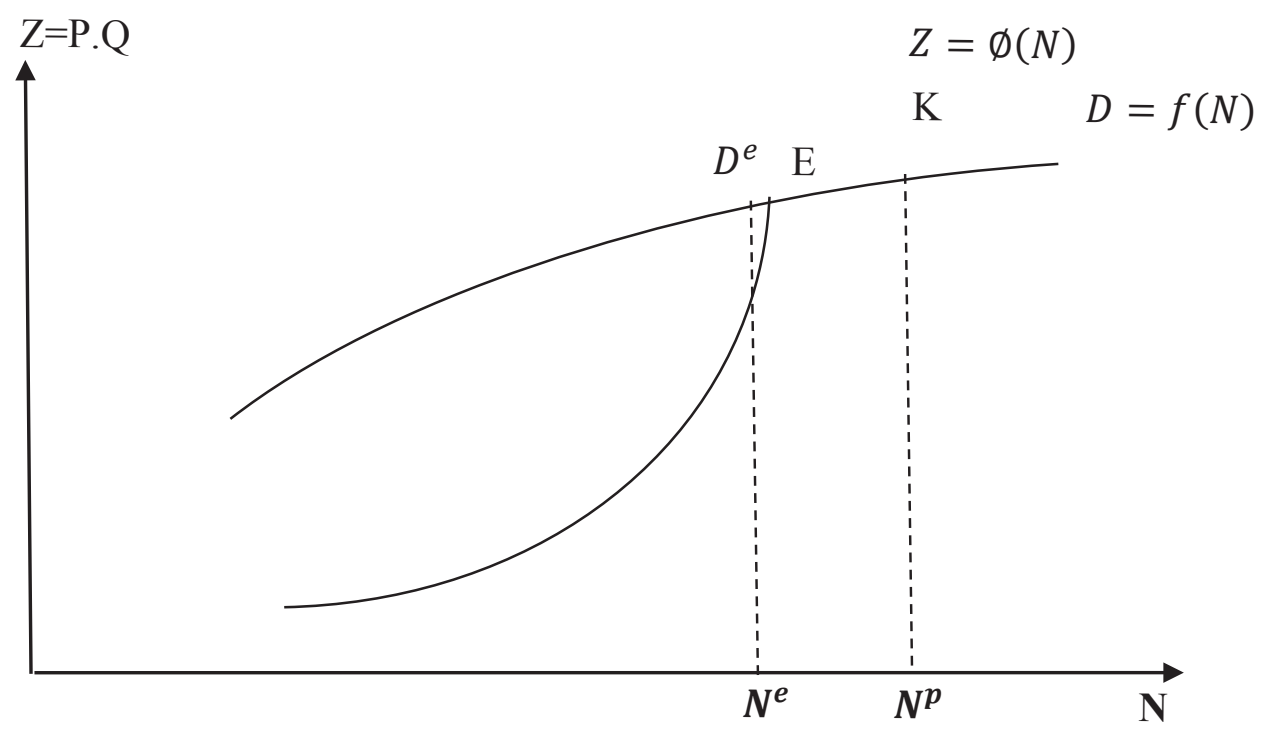

A Figura 1 contém as duas funções agregadas e o ponto resultante da interseção delas - o ponto de determinação da demanda efetiva ex ante. O volume de emprego $(\mathrm{N})$ acha-se localizado no eixo horizontal e o valor bruto da produção no eixo vertical. A curva da oferta agregada, $Z=\varnothing(N)$, e a curva da demanda agregada, $D=f(N)$, têm inclinações ascendentes, porém a inclinação da curva da demanda agregada possui uma inclinação menor do que a curva da oferta agregada na proximidade da interseção, como determina Chick (1993).

Isso é assim porque de outra forma não haveria estímulo à expansão ulterior, pois que a curva da demanda agregada à direita de $\mathrm{N}$ mais do que compensaria o custo de produção adicional. $\mathrm{O}$ ponto $\mathrm{E}$ resultante da interseção das curvas de oferta agregada e da demanda agregada é o ponto da demanda efetiva $\left(D^{e}\right)$ que determina o nível de emprego efetivo $\left(N^{e}\right)$. O ponto $\mathrm{K}$ representa o nível de pleno emprego. 
O volume de mão de obra $(\mathrm{N})$ que os empresários resolvem empregar depende da demanda efetiva (D) resultante da soma de duas espécies de gastos esperados quando os empresários decidem produzir: (1) do montante em valor monetário que se espera que seja gasto pela comunidade na compra de bens de consumo $\left(D_{1}\right)$; e do montante em valor monetário que se espera que seja aplicado em novos investimentos $\left(D_{2}\right)$. D é o valor monetário chamado de demanda efetiva que determina o volume do emprego efetivo.

Dado que $D_{1}+D_{2}=\mathrm{D}=\varnothing(N)$, em que $\varnothing$ é uma função da oferta agregada; $D_{1}$ (a relação entre a renda agregada de uma comunidade e a expectativa do que ela poderá gastar em bens de consumo) é uma função de $\mathrm{N}$, assim escrita, $D_{1}=x(N)$, a qual depende da propensão a consumir. Deduz-se que: $D_{2}=D-D_{2}=\varnothing(N-x(N)$.

Por conseguinte, o volume de emprego de equilíbrio depende (i) da função da oferta agregada $\varnothing$; ii) da propensão a consumir da comunidade, $x$; e do montante dos gastos dos investimentos. É essa a essência da TG de Keynes. Dessa forma, o sistema econômico pode encontrar um equilíbrio estável com um nível de emprego $\mathrm{N}$ inferior ao pleno emprego, ou seja, ao nível dado da interseção da função da demanda agregada e da função da oferta agregada.

\subsection{O princípio da demanda efetiva de Michal Kalecki}

A formulação do princípio da demanda efetiva em Kalecki aparece, claramente, em sua obra: "A Teoria da Dinâmica Econômica". Nesse livro, precisamente na seção 3, Kalecki (1983) apresenta os fatores determinantes dos lucros de um modelo simplificado de uma dada economia fechada e sem governo - em que é suposto que "os trabalhadores gastam o que ganham, e os capitalistas ganham o que gastam" - por meio da seguinte equação:

Lucros brutos $=$ investimento bruto + consumo dos capitalistas.

Qual é o significado lógico do sentido da determinação causal dessa equação? Quer dizer que os lucros, em um dado período de tempo, determinam os gastos de consumo e o investimento dos capitalistas? Ou o contrário? A resposta depende, como observa Kalecki, de qual dos itens esteja diretamente sujeito às decisões dos capitalistas. A resposta de Kalecki (1983, p. 36) é direta:

\footnotetext{
Ora, é claro que os capitalistas podem decidir consumir e investir mais num dado período que no procedente, mas não podem decidir ganhar mais. Portanto, são suas decisões (de gastos) quanto a investimento e consumo que determinam os lucros e não vice-versa.
}

Ou seja, recorrendo à lógica pura, Kalecki conseguiu formular de forma diferente o "princípio da demanda efetiva". De fato, fica claro que os capitalistas podem decidir quanto investirão e consumirão no futuro, mas não podem decidir de quanto serão suas vendas e seus lucros no futuro. Essa última decisão não pertence ao 
vendedor do bem, mas ao seu comprador.

Adaptando as equações de reprodução de Marx para a economia moderna, Kalecki (1977) tomou como hipótese simplificadora que os trabalhadores não poupam. Além disso, negligenciou a possibilidade de acumulação de estoques de produtos acabados e não vendidos, considerando-o um fenômeno passageiro.

Com isso, foi possível chegar à "equação de trocas" fundamental de Marx entre os departamentos produtores de bens de investimento (I) e bens de consumo dos capitalistas (II), de um lado, e o departamento produtor de bens de consumo dos trabalhadores (III), de outro.

Nesse esquema de reprodução, dada a distribuição da renda entre lucros e salários nos três departamentos, os gastos com bens de investimento (I), com bens de consumo dos capitalistas $(\mathrm{Cc})$ e com bens de consumo dos trabalhadores $(\mathrm{Cw})$ determinam a renda agregada $(\mathrm{Y})$, podendo ser assim expressa:

$$
\mathrm{Y}=\mathrm{I}+\mathrm{Cc}+\mathrm{Cw}
$$

Fazendo:

$$
\begin{aligned}
& \mathrm{P}=P_{1}+P_{2}+P_{3} \\
& \mathrm{~W}=W_{1}+\mathrm{W}_{2}+\mathrm{W}_{3} \\
& P_{3}=W_{1}+\mathrm{W}_{2}
\end{aligned}
$$

No caso, P1, P2 e P3 são os lucros brutos; W1, W2 e W3 são os montantes de salários dos três departamentos; e P e W são, respectivamente, o total dos lucros e o total dos salários. Assim, pode-se escrever:

$$
\mathrm{P}+\mathrm{W}=\mathrm{Y}=\mathrm{I}+\mathrm{Ck}+\mathrm{Cw}
$$

$\mathrm{Ou}$

$$
\mathrm{P}+\mathrm{W}-\mathrm{Cw}=\mathrm{I}+\mathrm{Ck}
$$

Supondo que os trabalhadores não poupam, então, $\mathrm{Cw}=\mathrm{W}$. Nessa situação, a equação (6) é reduzida para a seguinte expressão:

$$
\mathrm{P}=\mathrm{I}+\mathrm{Ck}
$$

Pela equação (7) fica claro que, em uma economia fechada e sem governo, os lucros dos capitalistas são determinados pelos seus próprios gastos em bens de investimento e de consumo. 


\section{O princípio da demanda efetiva como contra-ataque definitivo à lei de say dos economistas (neo)clássicos}

Usando as categorias ex ante e expost, pode-se dizer que é o empresário que toma a decisão (ex ante) quanto à quantidade de mercadorias que deverá produzir para vender aos compradores, e, por conseguinte, a quantidade de trabalhadores que deverá empregar com base na expectativa de quanto dessa produção ele espera vender com lucro aos seus consumidores que ele desconhece, e não tem nenhuma certeza se de fato eles comprarão os seus produtos quando estes estiverem prontos (bens acabados) para serem vendidos efetivamente, isto é, ex post.

Nesse contexto, qualquer empresário que tenha que tomar uma decisão prática a respeito de quanto deverá produzir de bens e serviços não terá uma única expectativa sobre qual será sua receita monetária esperada da venda de seus produtos de uma escala de produção determinada, mas várias expectativas hipotéticas que são formuladas com graus variáveis de probabilidade e precisão.

No momento da tomada de decisão, o empresário se defronta com duas curvas virtuais que Keynes denomina de:

i) curva do preço de oferta agregada: que representa a renda monetária necessária para que o empresário decida oferecer um determinado volume de emprego; e

ii) curva do preço de demanda agregada: que simboliza a renda monetária esperada pelo empresário quando decide oferecer um determinado volume de emprego.

Nesses termos, a curva de oferta agregada de bens e serviços representa as condições econômicas dos custos marginais e, como tal, a ampliação eleva a renda necessária para o empresário. Por outro lado, a curva da demanda agregada representa as expectativas dos empresários de quanto deverão receber sobre o volume de gastos das famílias (gastos de consumo) e das empresas (gastos de investimentos).

Além disso, o emprego aumenta com a expansão do lucro monetário do empresário enquanto a renda esperada pelo emprego adicional superar a renda necessária. Fica assim claro que a determinação do nível de emprego efetivo é uma atribuição dos empresários com base no que eles esperam vender no futuro, e não do mercado de trabalho como no modelo clássico.

Os economistas pré-keynesianos admitiam, antes da TG de Keynes, o desemprego temporário como uma consequência das imperfeições da oferta (devido à existência de monopólios ou das federações sindicais), antecipando preços em respostas rápidas a mudanças na composição da demanda do mercado de trabalho. Se o mercado de trabalho é livre para ajustar a taxa de salário, então as forças competitivas irão, pelo menos em longo prazo, forçar a mudança nos preços relativos de mercado de bens e serviços que refletem a diferença na composição da demanda, e, 
portanto, alcançar o equilíbrio de todos os mercados simultaneamente.

A implicação política dessa visão dos economistas clássicos é de que os governos não devem intervir para impedir que as forças dos mercados realizem essa tarefa a um menor custo. Para os economistas clássicos, a interferência do governo apenas posterga a restauração do pleno emprego. Mas o recorde do aumento do desemprego na Inglaterra, na década de 1920, convenceu Keynes que essa visão dos clássicos estava errada.

Mesmo se as condições da oferta fossem perfeitas, não se poderia confiar que a oferta criasse sua própria procura, como preconiza a Lei de Say. Por isso, daí em diante, o esforço de Keynes foi dirigido para explicar por que a determinação da demanda agregada não era idêntica à determinação da oferta agregada como presumiam os clássicos.

A principal diferença entre a Lei de Say e o PDE de Keynes na TG pode ser explicada pela diferença na forma e na posição da curva da oferta agregada em relação à curva da demanda agregada. A Lei de Say estabelece que os gastos (demanda agregada) são iguais ao total dos custos agregados de produção dos produtos da economia em geral, inclusive as rendas dos fatores e lucros dos empresários (oferta agregada).

Para demonstrar a invalidade da Lei de Say, vejamos: seja $\mathrm{Z}$ a representação da oferta agregada (ou expectativas dos empresários das receitas das vendas) em termos monetários; $\mathrm{D}$ a representação da demanda agregada (ou gastos planejados) também em termos monetários; $\mathrm{w}$ a taxa de salários nominais; e $\mathrm{N}$ o número de trabalhadores a contratar. Nessas condições, a função da demanda agregada pode ser assim representada:

$D=f_{\mathrm{d}}(w, N)$

A função da oferta agregada pode ser expressa da seguinte maneira:

$Z=f_{\mathrm{Z}}(w, N)$

De acordo com a Lei de Say, a equação (1) é igual a (2), tal que:

$f_{\mathrm{d}}(w, N)=f_{\mathrm{Z}}(w, N)$

Essa equação (3) é válida para todas as magnitudes de $\mathrm{N}$, isto é, para todas as magnitudes do produto e do emprego. Dito de outra forma, em uma economia regulada pela Lei de Say, o custo total da oferta agregada, isto é, o total dos gastos incorridos pelas empresas (supondo determinado grau de competição ou monopólio), para qualquer nível de emprego, é sempre determinado pelas vendas do produto. Essa situação pode ser vista na Figura 2: 
Figura 2 - Equilíbrio de Pleno Emprego da Lei de Say

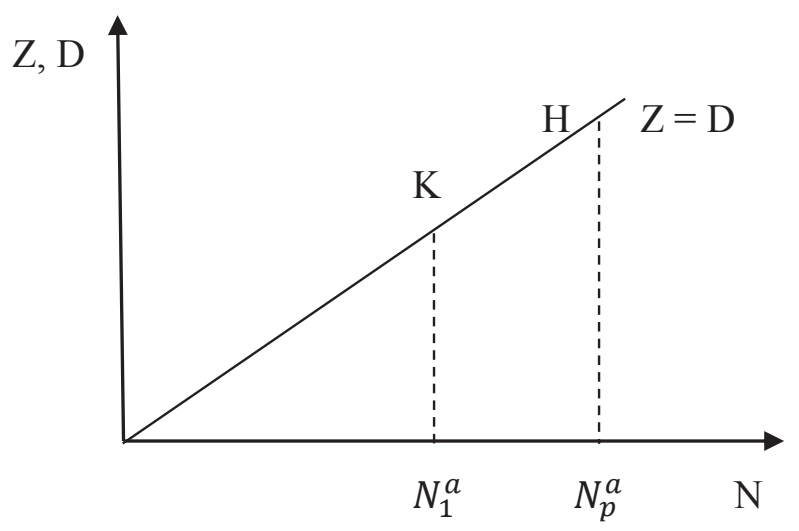

Como se pode notar, a função da oferta agregada $(Z)$ é representada pela linha reta com inclinação ascendente, indicando que quanto maior a expectativa da receita das vendas esperadas pelos empresários, mais trabalhadores $\mathrm{N}$ serão empregados; a função da demanda agregada (D) é representada pela linha reta, com inclinação ascendente, sugerindo que quanto maior o volume de emprego gerado mais os consumidores estão dispostos a gastar na compra de bens e serviços.

$\mathrm{Na}$ Figura 2, a função da oferta agregada e a função da demanda agregada são superpostas para representar o mundo da Lei de Say. A coincidência das curvas implica que, em qualquer ponto do tempo, o nível do emprego efetivado é $N_{1}^{a}$, o que implica que a demanda agregada observada é limitada ao ponto K. Ademais, qualquer expansão do nível de emprego $\mathrm{N}$ promovida pelos empresários para gerar um volume de produção adicional de bens (ponto $\mathrm{H}$ ) aumentará simultaneamente a demanda observada para o ponto $\mathrm{H}$, e com isso o pleno emprego $\left(N_{p}^{a}\right)$ poderá ser alcançado.

Para demolir a Lei de Say, Keynes construiu um modelo econômico no qual a função da oferta agregada não coincidiria com a função da demanda agregada, como visto na Figura 2. No modelo clássico, há apenas uma única categoria de gastos, os gastos com bens de consumo. Todo gasto de demanda não é só uma função da renda recebida (oferta) como é igual e determinada por esta.

Keynes também criou uma taxonomia à função da demanda agregada (D) desdobrando-a em dois componentes: o $D_{1}$ (gastos em compra de bens de consumo) e o $D_{2}$ (gastos em compra de bens de investimentos), tal que:

$$
D=D_{1}+D_{2}
$$

A categoria da demanda agregada de Keynes $\left(D_{1}\right)$ representa todos os gastos que dependem do nível da renda agregada e, portanto, do volume do emprego, $\mathrm{N}$, tal que:

$$
D_{1}=f_{1}(w, N)
$$


A segunda categoria da demanda agregada ( representa os gastos não relacionados com a renda e, portanto, com o emprego, isto é,

$D_{2} \neq f_{2}(w, N)$

O esforço de Keynes para invalidar a Lei de Say consistiu em demonstrar que a função da demanda agregada não somente não depende da renda agregada, $\quad D_{1}$ $=f_{1}(w, N)$, como não é igual à função da oferta agregada, $Z=f_{\mathrm{Z}}(w, N)$ para todos os níveis de emprego, $\mathrm{N}$. Isso é assim porque o $D_{2}$, a categoria que representa os gastos de investimentos, é positivamente maior do que zero, ou seja, $D_{2} \neq f_{2}(w, N)$.

Para demonstrar porque os gastos do $D_{2}$ não são relacionados com a poupança planejada, Keynes admite que as decisões dos agentes quanto ao futuro desconhecido são incertas porque tomadas num ambiente não ergódico. Nesse ambiente, os eventos econômicos futuros não podem ser antecipados a priori pelos sinais dos preços do passado ou do presente em vigor ou por meio dos métodos econométricos de previsão.

Nota-se que os gastos de investimento dependem das expectativas dos empresários ou do que Keynes denominou de animal spirit (ou "espírito animal”), pois tanto no curto período quanto no longo período, os gastos de investimentos não podem ser uma função da renda agregada corrente e, portanto, do volume do emprego.

A Lei de Say é um caso especial no qual $D_{2}=0$, desse modo, esse caso especial da doutrina clássica não é aplicável para a sociedade econômica na qual vivemos. O Princípio da Demanda Efetiva de Keynes, portanto, serve para demonstrar que, em um mundo não ergódico, a manutenção de ativos financeiros não reproduzíveis líquidos, que não são substitutos brutos dos produtos industriais, é a causa fundamental do desemprego involuntário.

\subsection{A relação entre demanda efetiva, propensão a consumir e multi- plicador da renda em Keynes: uma breve análise}

A teoria do consumo de Keynes está exposta, com riqueza de detalhes, no Livro III, sob o título: "A Propensão a Consumir". Explicado que o volume de emprego é determinado no ponto de interseção da função da oferta agregada com a função da demanda agregada, Keynes congela a função da oferta agregada, e enfatiza a função da demanda agregada esquecida pelos clássicos, de onde deriva a sua função consumo. Para Keynes (1982, p. 113):

A função de demanda agregada relaciona determinado volume de emprego com o produto das vendas que se espera realizar desse volume de empregos. O produto das vendas forma-se pela soma de duas quantidades - a soma que será despendida em consumo quando o emprego está em certo nível e a soma que se destinará ao investimento. 
Fica assim claro que a determinação do nível de emprego é uma atribuição dos empresários com base no que eles esperam vender no futuro no mercado de bens e serviços, e não do mercado de trabalho como no modelo clássico. Dessa forma, dos dois tipos de gastos esperados pelos empresários - de consumo e de investimento -,serão discutidos apenas os fatores que determinam os gastos de consumo quando o emprego se encontra em determinado nível com base no princípio da demanda efetiva.

A função mais conveniente usada por Keynes para tratar dos gastos de consumo das famílias foi a que relaciona o consumo em unidades de salário $(\mathrm{Cw}) \mathrm{com}$ a renda medida na mesma unidade, $\mathrm{Y}_{\mathrm{w}}$, correspondente a certo volume de emprego. Apesar de algumas restrições, Keynes acaba definindo como propensão a consumir, ex ante, como a relação funcional $\chi$ entre $\mathrm{Yw}_{\mathrm{w}}$ (determinado nível de renda medida em unidades de salários) e $\mathrm{Cw}$ (gastos de consumo que se torna da renda), tal que: $C_{w}=\chi\left(Y_{w}\right)$ ou $C=W \cdot \chi\left(Y_{w}\right)$.

Por isso, na visão de Keynes (1982), o valor do montante macroeconômico despendido pelas famílias, comprando bens e serviços de consumo, depende em parte do montante da renda, em parte de outros fatores objetivos que acompanham a renda, em parte de fatores subjetivos e da distribuição da renda. Esses motivos que impelem as famílias a gastarem parte de suas rendas agem de forma interativa.

Todavia, deixando de lado as atitudes subjetivas dos consumidores, e mesmo os outros fatores objetivos que não são aqui tratados, "a renda real é o principal fator determinante do consumo das famílias da função da demanda agregada, o resto são restrições", como observa Chick (1993, p. 113). Diante disso, Keynes (1982, p. 118) afirma:

Admitindo, pois, que a propensão a consumir é uma função bastante estável, de ma-
neira que, em geral, o montante do consumo agregado depende principalmente do
montante da renda agregada (ambos medidos em unidades de salário), e considerando
de importância secundária as variações na mesma propensão, qual é a forma normal
desta função? A lei psicológica fundamental em que podemos basear-nos com inteira
confiança, tanto a priori, partindo do nosso conhecimento da natureza humana, como
a partir dos detalhes dos ensinamentos da experiência, consiste em que os homens
estão dispostos, de modo geral e em média, a aumentar o seu consumo à medida que a
sua renda cresce, embora não em quantia igual ao aumento de sua renda.

Logo, aceitando a importância secundária das variações na propensão a consumir, pode-se dizer, de modo geral e em média, que as famílias aumentam o seu consumo na medida em que as suas rendas aumentam, porém não em valor igual ao aumento de suas rendas. Isso quer dizer que a razão $\frac{\Delta C w}{\Delta Y w}$ é positiva e varia entre
zero e um.

Essa razão é a propensão marginal a consumir ( $\mathrm{PMgC})$; e a razão entre o consumo agregado e a renda agregada, $\frac{C w}{Y_{w}}$, é a propensão média a consumir $(\mathrm{PMeC})$. 
Nesse caso, tendo como base Keynes (1982), a propensão marginal a consumir ex ante é importante porque permite que seja antecipado como se dividirá a renda.

Isso porque temos a seguinte relação:

$$
\Delta Y w=\Delta C w+\Delta I w
$$

Em que: $\Delta C$ e e $\Delta I w$ são incrementos do consumo e do investimento, o que permite uma dedução, dividindo a equação (1) por:

$$
\Delta Y w, 1=\frac{\Delta C w}{\Delta Y w}+\frac{\Delta I w}{\Delta Y w} \text { ou } \frac{\Delta C w}{\Delta Y w}=1 \frac{1}{\frac{\Delta Y w}{\Delta I w}}
$$

Fazendo: $k=\frac{\Delta Y w}{\Delta I w}$ e $\mathrm{c}=\frac{\Delta C w}{\Delta Y w}$

$$
\begin{aligned}
& \text { Então, k é o multiplicador da renda e c }=1 \frac{1}{k} \text { é a propensão marginal a } \\
& \text { consumir. }
\end{aligned}
$$

O multiplicador de investimento ex post, muitas vezes, é tratado mais pelos seus efeitos sobre a renda agregada e o emprego realizado. Dequech (2001) observa que, em um período contábil qualquer, é possível, depois de medir a renda e o investimento realizados e suas respectivas variações em comparação com um período contábil precedente, calcular a partir daí um multiplicador ex post e sua correspondente propensão marginal a consumir ex post.

Assim, a abordagem em termos ex post não é incompatível com a consideração de um período temporal. No entanto, do ponto de vista do empresário que toma decisões de produção e de investimento, o multiplicador de investimento ex ante é o que importa à determinação do emprego efetivo, segundo o PDE, principalmente em um momento da decisão de produzir (ou investir) em um ambiente marcado pela incerteza quanto ao futuro.

Nessas condições, portanto, o efeito esperado do multiplicador de investimento ex ante dificilmente irá coincidir com os resultados do multiplicador de investimento ex post. O multiplicador do investimento de Keynes revela que, em uma economia de mercado, quando se produz um acréscimo do investimento agregado, a renda agregada aumenta de um múltiplo em um montante igual a $\mathrm{k}$ vezes o acréscimo do investimento agregado.

Keynes (1982), ainda, sugere que a hipótese de estabilidade da função da propensão a consumir é só um caso especial dos períodos de curto prazo - que deve ser distinguida das funções das propensões a consumir mais permanentes quando as famílias não têm tempo suficiente para se adaptarem às mudanças das flutuações cíclicas. 
Nesse contexto, há duas formas de funções de consumo: "a função de consumo de longo prazo, $\mathrm{C}=\mathrm{cY}$, e a função de consumo de curto prazo, $\mathrm{C}=\mathrm{Ca}+\mathrm{cY}$, em que $\mathrm{Ca}$ é consumo autônomo que independe da renda, e $\mathrm{Ci}=\mathrm{cY}$ é o consumo induzido que depende da renda", como visto em Silva (1999, p. 179-180). Não obstante, Keynes (1982, p. 120) chama atenção para o seguinte aspecto:

Não devemos subestimar a importância do fato já assinalado anteriormente de que, enquanto o emprego é função do consumo e do investimento previstos, o consumo é, coet. par., função da renda líquida, isto é, do investimento líquido (sendo a renda líquida igual ao consumo mais o investimento líquido). Em outras palavras, quanto maior for a provisão financeira que se julgue necessário constituir antes de calcular a renda líquida, menos favorável será para o consumo, e, portanto, para o emprego, um volume determinado de investimento

E conclui (1982, p. 80):

O consumo - para repetir o óbvio - é o único fim e objetivo da atividade econômica. As oportunidades de emprego estão necessariamente limitadas pela extensão da procura agregada. A demanda agregada só pode ser derivada do consumo presente ou das reservas para o consumo futuro. $\mathrm{O}$ consumo que podemos prover vantajosamente com antecedência não pode estender-se indefinidamente no futuro. Não podemos, como sociedade, prover consumo futuro por meio de expedientes financeiros, mas apenas mediante a produção física corrente.

Nota-se, portanto, que o excesso de prudência financeira das firmas pode causar restrições à demanda agregada e, assim, reduzir a renda agregada com consequências para o nível de emprego. Assim, fora as variações no nível de renda agrega$\mathrm{da}$, um aumento no montante absoluto da renda agregada pode alargar a diferença entre a renda agregada e o consumo agregado, de modo que uma proporção maior da renda agregada seja poupada.

É preciso distinguir as mudanças dos gastos de consumo causadas por uma variação da renda - quando a propensão marginal a consumir não é estável - das mudanças dos gastos de consumo causadas pela propensão marginal a consumir quando não há variação na renda.

A propensão a consumir tende a ser tanto mais alta quanto mais baixa a faixa da renda. Esse é o motivo da importância de uma distribuição da renda dirigida para as populações mais pobres resultar em um aumento no consumo agregado. Ademais, se a propensão marginal a consumir aumenta ceteris paribus, o multiplicador do investimento também aumenta, o que contribuirá para o aumento da renda agregada.

Keynes (1982, p. 139-140) utiliza o princípio geral do multiplicador assim: 
Entretanto, é pelo princípio geral do multiplicador que se deve explicar como as flutuações no montante do investimento, comparativamente pequenas em proporção à renda nacional, podem gerar alterações no emprego e na renda agregada de amplitude muito maior que elas próprias.

Nessa citação, Keynes refere-se ao efeito multiplicador dos gastos de investimento sobre os gastos de consumo, e supõe dois casos: um em que é previsto um aumento do investimento tal para que as indústrias de bens de consumo cresçam no mesmo ritmo das indústrias de bens de investimento, mas sem aumento dos preços dos bens de consumo que o derivado do aumento da quantidade produzida nas condições de rendimento decrescente; e outro em que não é previsto um aumento dos bens de investimento e seus efeitos sobre os bens de consumo.

É evidente que essa última iniciativa só produz todos os seus efeitos na economia, sobretudo no emprego, depois de certo lapso de tempo. Keynes observou que essa evidência origina, muitas vezes, alguma confusão entre a teoria lógica do multiplicador do investimento - cuja aplicação se dá continuamente, sem defasagem, todo o instante - que pode ser representada por $\frac{\Delta Y}{\Delta I}=\frac{1}{1 \mathrm{c}}=k$; e a teoria dinâmica do multiplicador do investimento - que resulta de uma expansão das indústrias de bens de investimentos e cujo efeito sobre as indústrias de bens de consumo verifica-se de modo gradual, com defasagem, após um determinado intervalo de tempo - que pode ser representada por $\frac{\Delta Y}{\Delta I}=1+c+c^{2}+\ldots \ldots .+c^{n}=\frac{1}{1 c}$, como
visualizado em Possas (1987).

Percebe-se que uma expansão nas indústrias de bens de investimentos determina uma série de aumentos no investimento agregado, que ocorrem em períodos sucessivos num determinado período de tempo, e uma série de valores da propensão marginal a consumir nesses períodos sucessivos que difere tanto do que seriam esses valores, se a dita expansão estivesse sido prevista, quanto do que serão quando a economia a ficar estabilizada em um novo e seguro nível de investimento agregado. Keynes (1982, p. 140), porém, faz importante comentário:

Porém, em cada período, a teoria do multiplicador continua sendo válida no sentido de que um acréscimo da renda agregada é igual ao produto do acréscimo do investimento agregado e do multiplicador determinado pela propensão marginal a consumir.

\section{Considerações finais}

Do ponto de vista teórico, o erro da teoria clássica sempre esteve associado à crença na Lei de Say de que "toda oferta cria sua própria procura". Por esse princípio das leis do mercado, venerado pelos clássicos, não poderia haver desemprego, pois 
sempre que uma nova unidade de produção é criada, ela cria o seu próprio emprego. Tal hipótese formulada nunca foi demonstrada.

$\mathrm{Na}$ verdade, dizer que toda oferta cria a sua procura significa afirmar, em outras palavras, que toda venda corresponde a uma compra. Isso é um truísmo, ou seja, uma verdade em si, pois ninguém de bom senso pode deixar de reconhecer que não pode ocorrer venda sem compra e vice-versa.

De fato, a Lei de Say quando afirma que "toda oferta cria a sua própria procura” está dizendo que toda oferta causa a sua própria procura. Ora, nesse ponto, há um erro de lógica da Lei de Say não percebido pelos economistas clássicos. Tal erro consiste no fato, não observado pelos clássicos, de que para que o ato mercantil-monetário se realize, quando se confronta o comprador e o vendedor, a decisão final não depende nunca do vendedor que é possuidor da mercadoria, e sim do comprador, possuidor do dinheiro.

Logo, é a compra que determina a venda ou é a demanda efetiva que determina a oferta, e não o contrário. É esse o Princípio da Demanda Efetiva de Keynes que se opõe à Lei de Say, o divisor de águas entre Keynes e os clássicos. Keynes, ainda, observa que o diagnóstico da crise do capitalismo que levou à Grande Depressão norte-americana nos anos 30 não estava no mercado de trabalho, mas sim no departamento de bens e serviços.

O tempo tratou de mostrar que o desemprego em massa da economia norte-americana foi um problema de insuficiência de demanda efetiva que inibia o animal spirit do empresário investidor em um ambiente de incerteza. Na TG, a demanda efetiva, em uma economia fechada, depende das decisões de gastos em consumo e investimento produtivos.

No entanto, enquanto os gastos de consumo dependem de renda agregada, os gastos de investimentos dependem das expectativas da eficiência marginal do capital (taxa de lucro esperada), da taxa de juros corrente e do estado de confiança dos agentes com relação ao futuro incerto.

A principal conclusão é que o PDE de Keynes continua atuando como instrumento de grande relevância acadêmico-científica, sobretudo para demonstrar que, em um mundo não ergódico, a manutenção de ativos financeiros não reproduzíveis líquidos, que não são substitutos brutos dos produtos industriais, são a causa fundamental do desemprego involuntário. Ou seja, a ausência de perfeita flexibilidade dos preços não é uma condição necessária, como supõem os clássicos, para demonstrar a existência de desemprego.

\section{Referências bibliográficas}

CHICK, Victoria. Macroeconomia após Keynes: um reexame da teoria geral. Rio de Janeiro: Forense Universitária, 1993. 
DEQUECH, David. O multiplicador do investimento: um texto didático. Campinas, SP, IE/ UNICAMP, 2001.

GARLIPP, José Rubens Damas. Keynes e a Economia Monetária. In: I Encontro Internacional da Associação Keynesiana Brasileira, 2008, Campinas-SP. Anais do I Encontro Internacional da Associação Keynesiana Brasileira. Campinas-SP: Unicamp, v. 1. p. 01-20, 2008.

HARROD, Henry Roy Forbes. La Vida de John Maynard Keynes. México, Fondo de Cultura Económica, 1958.

KALECKI, Michal. A determinação dos lucros e da renda nacional. In: Teoria da Dinâmica Econômica. São Paulo, Abril Cultural. (Os Economistas), 1983.

KEYNES, John Maynard. A teoria geral do emprego. In: Keynes: Economia. Tomás Sczmrecsányi. São Paulo, Ática, 1978.

KEYNES, John Maynard. A Teoria Geral do Emprego, do Juro e da Moeda. São Paulo, Atlas, 1982.

KEYNES, John Maynard. The Collected Writings of John Maynard Keynes, 30 volumes. Londres: MacMillan e Cambridge: Cambridge University Press. Volumes identificados como $\mathrm{CW}$, seguidos pelo número respectivo.

MARX, Karl. O Capital: Crítica da Economia Política: Livro 1: O processo de produção do capital. Rio de Janeiro, Civilização Brasileira, 1980.

POSSAS, Mário Luiz; BALTAR, Paulo Eduardo de Andrade. Demanda Efetiva e Dinâmica em Kalecki. Pesquisa e Planejamento, vol.11, nº 1, abril, 1981.

POSSAS, Mario Luiz. Dinâmica da economia capitalista: uma abordagem teórica. São Paulo, Brasiliense, 1987.

SILVA, Antônio Carlos Macedo. Macroeconomia Sem Equilíbrio. Petrópolis, Rio de Janeiro, Vozes; Campinas, São Paulo, FECAMP, 1999. 